\title{
DE VUELTA A LA ECONOMÍA POLÍTICA
}

\author{
Katherine Flórez Pinilla \\ Maestría en Derecho Económico, Universidad Externado de Colombia. (Colombia). Economista. \\ Universidad Industrial de Santander. (Colombia). Docente investigadora, Facultad de Derecho, \\ Universidad Santo Tomás, Bucaramanga. (Colombia) \\ Correo electrónico: katheflorezpinilla@gmail.com
}

\begin{abstract}
Resumen
Mises y Hayek proponen una revaluación a los postulados de la economía clásica y a aquellos que emergen de la posterior aplicación del método científico,para enmendar las fallas que dieron origen a las formulaciones teóricas de Marx y a la consolidación de la ciencia económica como un tipo de ingeniería social. Dichodesarrollo en palabras de Mises corresponde a "problemas mal enfocados y peor resueltos"1. Las propuestas teóricas y metodológicas de la escuela austriaca, parten del individuo, de su capacidad de raciocinio, de aprehensión del conocimiento y de sus motivaciones, con lo cual moldean un esquema lógico y comprensivo de la acción del hombre en la sociedad, del papel de la información y la incertidumbre, así como los procesos de adaptación en la explicación de las elecciones humanas. El método apriorístico-deductivo constituye una alternativa para el estudio de la economía y de las instituciones que lleva a revaluar los fundamentos epistemológicos del pensamiento económico, los alcances y límites del abordaje teórico y la importancia de otras disciplinas para la realización de éste.
\end{abstract}

Palabras clave: Acción humana, método apriorístico-deductivo, individualismo metodológico, epistemología.

Clasificación JEL: B12; B13; B41; B53.

\begin{abstract}
Mises and Hayek propose a revaluation to the postulates of the classic economy and to those that emerge of the later application of the scientific method, to amend the faults that gave origin to Marx's theoretical formulations and to the consolidation of the economic science as a type of social engineering. The above mentioned development in Mises's words corresponds to " problems badly focused and worse decisive. The theoretical and methodological offers of the Austrian school, they depart from the individual, from his capacity of reason, from apprehension of the knowledge and from his motivations, with which they mold a logical and comprehensive scheme of the action of the man in the company, of the paper of the information and the uncertainty, as well as the processes of adjustment in the explanation of the human choices. The hasty-deductive method constitutes an alternative for the study of the economy and of the institutions that leads to revaluing the foundations epistemológicos of the economic thought, the scopes and limits of the theoretical boarding and the importance of other disciplines for the accomplishment of this one.
\end{abstract}

Key Words: Action humanizes, hasty-deductive method, methodological individualism, epistemologi.

\section{Résumé}

Mises et Hayek proposent une réévaluation aux postulats de l'économie classique et à ceux qui sortent de l'application postérieure de la méthodes cientifique, pour corriger les failles qui ont donné naissan ceaux formulations théoriques de Marx et à la consolidation de la science économique comme un type d'ingénierie sociale. Le dit développement dans des mots de Mises communique à "des problèmes mal mis aupoint et pis résolus. Les propositions théoriques et méthodologiques de l'autrichienne école, ils partent de l'individu, de sa capacité de raisonnement, d'appréhension de la connaissance et de ses motivations, avec lequel ils moulent un schéma logique et compréhensif de l'action de l'homme dans la société, du papier de l'information et l'incertitude, ainsi que les processus d'adaptation dans l'explication des élections humaines. La méthode apriorique - déductive constitue une alternative pour l'étude de l'économie et des institutions qui emporte à revaluar les fondements epistemológicos de la pensée économique théorique, les portées et les limites de l'abordage et l'importance d'autre discipline pour la réalisation de celui-ci.

Mots-clés: l'Action humanise, une méthode apriorique - déductive, un individualisme méthodologique, epistemología.

1 MISES, Ludwing. La acción humana. Tratado de Economía [SéptimaEdición]. Madrid. Unión Editorial S.A. 2004.

Recibido, Agosto 30 de 2012; Aprobado, Octubre 12 de 2012. 

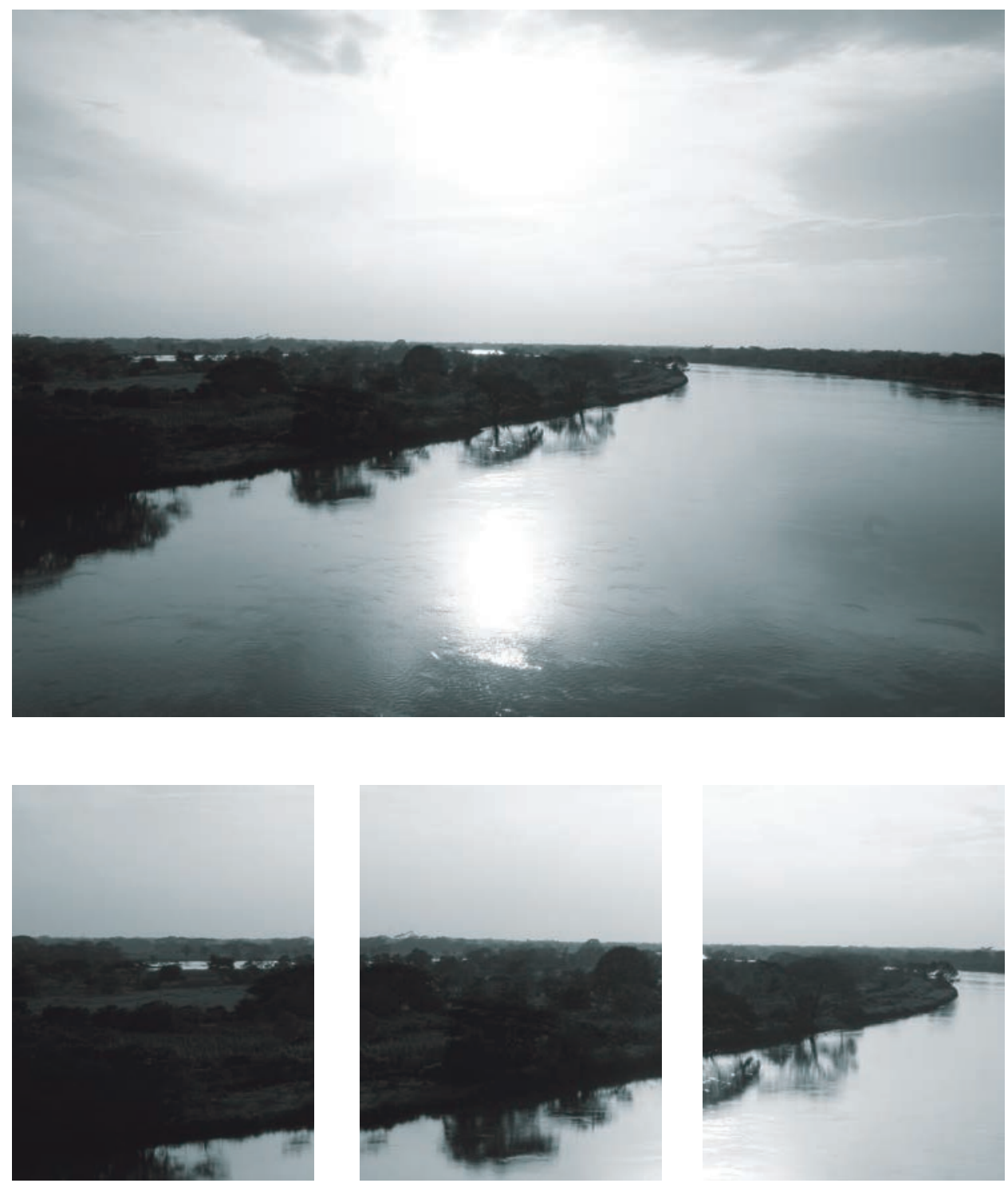

Rio Magdalena - Mompóx - Colombia

Martín Emilio Hernández Manrique 


\section{DE VUELTA A LA ECONOMÍA POLÍTICA*}

Katherine Flórez Pinilla

\section{INTRODUCCIÓN}

El propósito de la presente ponencia se centra en identificar los elementos metodológicos que llevaron al desvanecimiento del estudio de la economía política, ciencia fomentada por los precursores de la economía clásica. Para su alcance se utilizó como marco referencial los postulados de la llamada escuela austriaca expuesta principalmente por Ludwing von Mises y Friedrich von Hayek el siglo pasado quienes, además de realizar un propuesta metodológica alternativa para el estudio de la economía, muestran las debilidades y las limitantes que ostenta el estudio desde una perspectiva cartesiana y la ha llevado a cierto reduccionismo que desnaturaliza tanto el objeto de estudio como la labor propia del economista.

Una de aquellas labores olvidadas por los economistas ha sido el estudio de las instituciones legales, instituciones políticas y la filosofía misma que posibilita, o mejor, que están implícitas en el funcionamiento de la economía, de los mercados, del desarrollo económico y el bienestar. Es decir, se han dejado a un lado los elementos que hacen de la economía una ciencia humana. Antes del siglo XIX el análisis económico no se podría prescindir del estudio de la cuestión institucional, era la llamada economía política, tal como reseña Hayek se concebía como "una parte de la jurisprudencia"2.

\footnotetext{
* El presente texto se deriva de la investigación desarrollada por la autora en su Maestría en Derecho Económico, Universidad Externado de Colombia (2011-2012). Proyecto de Investigación: Análisis económico del derecho de patentes: un aporte desde la escuela austriaca.

2 Así lo menciona Hayek en su prólogo a los Principios de economía política de Carl Menger.
} 
Si bien algunos enfoques actuales de la economía incluyen el fenómeno institucional, su acercamiento parte del determinismo metodológico lo cual le ha asignado a la economía la posibilidad de diseñar instituciones, el llamado diseño institucional en boga ${ }^{3}$, producto inmediato del enfoque estándar que pretende solucionar los problemas habituales del comportamiento humano con la intervención estructurada. Como se verá el enfoque austriaco si bien se centra en el análisis de las instituciones, sus efectos en el comportamiento y la forma como los humanos las estructuran a partir de procesos espontáneos, de procesos de aprendizaje y prueba y error, realiza una crítica a dichas pretensiones de la ciencia estándar imposibles de alcanzar con el método utilizado.

\section{LA FALLA DEL CIENTIFICISMO EN EL DESARROLLO DE LA CIENCIA ECONÓMICA}

\subsection{Teoría objetiva del valor}

Que la teoría del valor de Adam Smith y David Ricardo haya sido el punto de partida para establecer teoría marxista sobre el capital, el funcionamiento y evolución de la economía, constituye un punto fuertemente criticado desde la escuela austriaca que precedió Carl Menger y expusieron entre otros, Ludwing von Mises y Friedrich Hayek, no sólo porque dota de elementos a fundamentación marxista sino porque constituye pieza clave en la versión predominante de ciencia económica tal como la conocemos hoy en día.

El argumento de Menger contra los clásicos constituye el núcleo duro de la teoría económica austriaca, a saber, su formulación de la teoría subjetiva del valor, que a diferencia de la explicación de la formación de los precios según valoraciones objetivas, los austriacos evidencian una, a partir del subjetivismo que atribuyen inherente a la forma de elección de los humanos. Mises afirma que los resultados obtenidos por los clásicos parten de concebir la formación de los precios, y en general todos los fenómenos del mercado, como “(...) un hecho objetivo; un fenómeno más del mundo externo, una condición inherente a las cosas, que, por lo tanto, podía ser ponderado y medido"

Los clásicos valoraban los precios de los bienes según la combinación de factores de producción aplicados a su producción: la tierra, el capital, el trabajo; por tanto, al constituir en "el corto plazo" la tierra y el capital fuentes estables (fijas) en la producción la teoría de Smith supone que el valor de las mercancías está determinada

3 Posibilidad permitida por metodologías como el análisis económico del derecho y el publicchoice.

4 MISES, Ludwing. La acción humana. Tratado de economía. Unión Editorial. [Séptima ediciónTrad.]. Madrid. P., 265 
por el trabajo (teoría del valor-trabajo) ${ }^{5}$. En este sentido, vale citar las palabras de Smith que demuestran su intención:

"El precio real de cualquier cosa, lo que realmente cuesta al hombre que ha de adquirirla, es la fatiga y el trabajo de su adquisición. Lo que vale realmente para el que la tiene ya adquirida, y ha de disponer de ella, o ha de cambiar por otra, es la fatiga y el trabajo que a él le ahorra, y cuesta al otro."

No obstante, de este postulado se deriva la dicotomía de Smith en la determinación del valor, puesto que mientras por un lado, afirmaba que los bienes poseían un valor en uso, determinado por la satisfacción de las necesidades, es decir, por la utilidad total, por otro lado atribuía a los mismos un valor en cambio determinado por la escasez y el grado de división de trabajo inmerso para su producción. Sin embargo, valor en uso y valor en cambio no coincidían en la realidad, hecho reflejado en la famosa paradoja del valor entre el agua y los diamantes, mediante la cual se reflejaba que si bien, el agua poseía un elevado valor de uso (por ejemplo en la satisfacción de la sed) éste no era reflejado por su valor en cambio (en principio un bien no escaso y con poca mano de obra necesaria para su obtención), mientras que los diamantes con un valor de uso mínimo poseían un valor de cambio elevado. Menger ${ }^{7}$ resolvería tal cuestión un siglo después mediante el razonamiento que permite su concepto de utilidad marginal.

Smith dejaría tal paradoja para dedicarse a explicar el valor en cambio. Atribuye su origen al proceso de producción, por lo cual, atribuyó a la cantidad de trabajo disponible o adquirible la explicación del mismo, a este lo denotó precio real de las mercancías, el precio nominal estaría dado por el dinero que se intercambia para su adquisición.

Al asumir el trabajo como valor estándar de los bienes, los clásicos lo consideran como una variable con un carácter no específico lo cual, desde la óptica de Mises, constituye un desacierto en la teoría puesto que "no se puede generalizar al hablar de trabajo humano", de este modo se desconocen las diferencias y las clases en la capacidad laboral de los hombres y de sus innatas cualidades en tal ámbito, por lo cual afirma: "No se pagan salarios por el puro trabajo invertido, sino por la obra realizada mediante labores ampliamente diferenciadas entre sí, tanto cuantitativa como cualitativamente consideradas" .

$5 \quad$ Es de recordar que antes de Smith, en especial la tradición fisiócrata atribuía el valor y la riqueza al factor tierra.

6 SMITH, Adam. Investigación de la naturaleza y causa de la riqueza de las naciones. Libro I. Capítulo V. P., 49.

7 MENGER, Carl. Principios de economía política. 1871. [Edición disponible en Web]

8 MISES, Ludwing. La acción humana. Tratado de economía. Unión Editorial. [Séptima ediciónTrad.]. Madrid. P., 160. 
Para los austriacos así como las capacidades no son las mismas en cada individuo, tampoco lo son las necesidades. Las especiales condiciones características y, por tanto, las valoraciones de cada individuo serían pieza clave para la formulación de la teoría subjetiva del valor que promulgaran. Al existir tal diferencia, las cosas y los bienes serían apreciados de forma diferente por las personas.

En este sentido, Menger afirma que el significado del valor es "metafórico" puesto que "lo único que tiene significación es la satisfacción de nuestras necesidades", este valor sólo se encuentra asociado a aquellas, dicha valoración es desigual en grado en que otorgue satisfacción al hombre, por lo cual afirma:

"El valor de un bien concreto o de una determinada cantidad parcial de la masa total de bienes (...) es igual a la significación que para el mencionado sujeto tiene la satisfacción de las necesidades menos importantes que puede alcanzarse con aquella cantidad parcial y todavía no está asegurada por la cantidad total. La satisfacción de estas necesidades depende, efectivamente por lo que hace al sujeto económico en cuestión, de la disposición sobre el bien concreto correspondiente o sobre la correspondiente cantidad de bienes." 10

Se dice que Jean Batiste Say sería el primero de la tradición clásica en percatarse de la poca oportunidad de la teoría objetiva del valor de Smith: "Puntualizó, en forma clara pero imprecisa, que primero está el valor de las cosas y luego el precio. Que las personas incurren en costos porque primero le dan valor a las cosas."11 Por lo cual, el proceso de valoración iniciaba con la valoración del bien final por parte de los consumidores y éste se impregnaba en la valoración a los factores de producción implicados ${ }^{12}$, no al contrario como lo mostraban las premisas de Smith.

Ricardo afirmaba además que la formación del valor de los bienes difería en el comercio exterior respecto del interior, basado en que "la productividad de los factores de producción, técnicamente posibles de trasladar, es diferente según los lugares donde aquellos se ubiquen y, que dichos factores por razones institucionales, tienen restringida su movilidad"13, al igual que Smith, Ricardo falla, al atribuir el valor de los bienes a la productividad y a la libre movilidad de capitales, la segunda

$9 \quad$ Ibíd., p., 99.

10 Ibíd.

11 CACHANOSKY, Juan C. Historia de las teorías del valor y el precio. Revista Libertas 22. Mayo 1995. Instituto Universitario ESEADE www.eseade.edu.ar

12 En este sentido Cachanosky citando a Menger resalta: “(...) si un diamante fue encontrado accidentalmente o si se lo obtuvo de una mina de diamantes con el empleo de mil días de trabajo es completamente irrelevante para su valor. En general, nadie, en su vida cotidiana, pregunta por la historia del origen de un bien para estimar su valor, sino que toma en cuenta solamente el servicio que el bien le brindará y al que tendría que renunciar si no tuviese el bien a su disposición". CACHANOSKY, Juan C. La escuela austriaca de economía. S.f. P., 11. Disponible en sitio web http://www.hacer.org/ 
razón, según Mises válida en su época, no corresponde en ningún principio para la determinación del valor.

Así mismo, se atribuye a Ricardo la adopción de tesis cientificistas tales como "la ley malthusiana de la población y la ley de los rendimientos decrecientes de la tierra."14 Para la valoración de los factores de producción: tierra, capital y trabajo. Aunque también postula una teoría del valor-trabajo al igual que Smith, su versión diferiría al considerar el valor de los bienes dada por el costo del trabajo, medido por las horas-hombre designadas para su producción, dejando de lado los costos de producción que también inciden en Smith como la renta de la tierra, del capital y las ganancias.

\subsection{Utilitarismo}

Otra falla atribuida a los clásicos (con excepción de Smith), fue el ferviente utilitarismo desarrollado a final del siglo XVIII y en el siglo XIX. Un ejemplo de tal emancipación se encuentra en el marqués de Beccaria quien iniciaría su obra con la presunción: "La felicidad mayor colocada en el mayor número debiera ser el punto a cuyo centro se dirigiesen las acciones de la muchedumbre"15. La misma frase que caracterizaría el utilitarismo de Jeremy Bentham años más tarde y que continuaría John Stuart Mill.

Si a esta presunción la acompaña aquella según la cual la búsqueda del interés individual va en desmedro del interés colectivo, quebrando el significado de la mano invisible de Smith según la cual el egoísmo, como motivo humano individual, conseguía efectos no esperados como el bienestar colectivo ${ }^{16}$, se inicia un movimiento a favor del diseño de la regulación del comportamiento individual como medio para el alcance de la mayor felicidad colectiva. Estas ideas distanciarían radicalmente a Bentham de Smith, puesto que el segundo concebía la búsqueda del interés individual como medio natural de la cooperación social, demostrando la poca oportunidad de la intervención estatal directa para este fin.

En este sentido, Posner afirma: "El utilitarismo sostiene que el valor moral de una acción (o de una práctica, institución o ley) debe ser juzgada por su efecto en la promoción de felicidad (mayor placer sobre dolor)." ${ }^{\prime 17}$. Tal felicidad como resultado

14 LACHMANN, Ludwig. El significado de la escuela austríaca de economía en la historia de las ideas. Revista Libertas 27. Octubre 1997. Instituto Universitario ESEADE www.eseade.edu.ar.

15 BONESSANA, Cessare. Tratados de los delitos y las penas. 1764. (Edición de 1993). Argentina: Editorial Heliasta. P., 55.

16 "No es la benevolencia del carnicero, del cervecero o del panadero la que nos procura el alimento, sino la consideración de su propio interés. No invocamos sus sentimientos humanitarios sino su egoísmo; ni les hablamos de nuestras necesidades, sino de sus ventajas". SMITH, Adam. Investigación de la naturaleza y causa de la riqueza de las naciones. Libro I. Capítulo V. 1794. P., 23.

17 POSNER, Richard. Utilitarismo: economía y teoría jurídica. En Derecho y Economía: una revisión de literatura Andrés Roemer [comp.]. 2000. México: Fondo de Cultura Económica. P., 160. 
de la adición de felicidades individuales, las cuales Bentham pretendía medir u objetivizar, indicaba el grado en que el gobierno debía intervenir para proveerla. La posibilidad de asignar valores cardinales a la felicidad es resultado del naciente cientificismo en la economía política que perdura hasta nuestros días.

\subsection{Objetividad de los fenómenos sociales y mecanicismo}

El subjetivismo valorativo que caracteriza a los austriacos en contra de los clásicos, no sería un método aplicado sólo a la determinación del valor de los bienes, éste es aplicable a todas las esferas de la acción humana, puesto que se desprende de una concepción del hombre y entorno fusionada y no desligada como plantea el racionalismo constructivista ${ }^{18}$ con la aplicación del método científico desde Descartes $^{19}$ a la explicación de los fenómenos sociales. Al separar al hombre de la realidad, pretende formar juicios objetivos sobre los fenómenos, dividirlos en sus partes más ínfimas (simplificación), abordarlos mediante identificación de causas y efectos (mecanicismo) y determinar su grado de ajuste u asociación.

Sobre la pretensión de determinar la causa de todos los fenómenos, Mises arguye que existen fenómenos “(...) que no pueden ser analizados ni referidos a otros: son presupuestos irreductibles" ${ }^{20}$ como sucede con los asociados a la acción humana. Las personales valoraciones inciden también en la concepción del mundo, por lo cual es fácil explicar como "Idénticos fenómenos exteriores provocan reflejos humanos diferentes y hechos dispares dan lugar a idénticas respuestas humanas. Ignoramos el por qué" 21 .

Por tanto, Mises hace un llamado a admitir la racionalidad del hombre, pero también admitir su finitud ${ }^{22}$, limitaciones e infalibilidad que aplica no sólo como descripción del individuo como "objeto" de estudio sino como investigador de dicho objeto.

Tales esquemas teóricos subyacentes del mecanicismo conciben las cosas o objetos del mundo susceptibles a la manipulación y abordaje (como si se tratase

18 Término atribuido por Hayek para enunciar el movimiento del método científico a la explicación de fenómenos sociales. A este respecto Hayek afirma: "Descartes había enseñado que sólo deberíamos creer en lo que se puede probar. Aplicada en forma general al campo de la moral y de los valores, su doctrina significó que sólo deberíamos aceptar como obligatorio aquello que pudiéramos reconocer como una concepción racional para un propósito reconocible.” HAYEK, Friedrich. Los errores del constructivismo. 1970. Traducción publicada en Estudios públicos.

19 Descartes fue el más contundente predecesor de tal enfoque al proponer un método de aprehensión del conocimiento por medio de cuatro reglas: "reconocer como verdadero solo aquello con la suficiente evidencia (...), división de los problemas en tantas partes como fuese necesario, ordenar los conocimientos de los más sencillos a los más complejos y realizar verificaciones de cada una las deducciones realizadas". DESCARTES, Renato. El discurso del método. p., 31

20 MISES. Op. Cit., p., 22.

21 Ibíd., p., 23.

22 En cuanto a tal concepción de ser, Zanotti pretende demostrar en su tesis que las bases filosóficas de la praxeología de Mises se remontan a la metafísica y la antropología de Santo Tomás de Aquino, la cual establece la naturaleza finita del ser. 
de fenómenos sencillos ${ }^{23}$ ), que pretenden aplicar en el terreno de la economía. Los austriacos son enfáticos en afirmar que los problemas de la acción humana se remiten a las ideas de los seres humanos sobre sus fines y medios, por lo cual no son observables y se pueden interpretar y abordar de distintas formas según las teorías, concepciones o preconcepciones que se tengan (entran en la órbita de lo que denomina Hayek fenómenos complejos).

La mente humana al no poder auto-explicarse, ni auto-reproducirse no puede explicar satisfactoriamente el orden, puesto que ésta ha sido moldeada por variedad de factores ${ }^{24}$, hábitos y disposiciones para actuar de un modo regido por normas ${ }^{25}$ (conocimiento tácito) que llevan a apreciar el mundo de forma diferente. En este sentido, Hayek "estigmatiza la noción de esencia o realidad absoluta como inútil o perjudicial en la ciencia y en la filosofía. El objetivo de la ciencia sólo puede ser el desarrollo de un sistema de categorías o principios, a la larga organizados enteramente sobre una base deductiva, que sea adecuado para la experiencia que se procura ordenar" ${ }^{26}$. Hayek afirma así como la mente humana es un producto de la evolución social, la acción en el mundo, emanada de la misma, también se forma a partir de procesos de de prueba y error:
“(...) la mente humana es, en sí misma, un producto evolutivo y que su estructura es, por lo tanto, variable y no constante. Los principios estructurales o las categorías fundamentales que nuestra mente contiene no deberían, entonces, ser interpretados al modo cartesiano como axiomas universales y necesarios que reflejan las necesidades naturales del mundo sino, en su lugar, como la constitución de adaptaciones evolutivas del organismo humano hacia el mundo en el que habita."27

Para los austriacos no existe conocimiento perfecto puesto que "la necesaria ignorancia del hombre le ayuda en la consecución de sus fines (...) la civilización comienza cuando en la persecución de sus fines el individuo puede sobrepasar los límites de su ignorancia aprovechándose de conocimientos que no poseía" 28 .

No obstante, el método científico y su desarrollo asume una posición dualista sobre la relación mente y cosmos, es decir, que "la mente y el cosmos eran dos entes diferentes o, en términos cartesianos, que la res extensa era independiente de la res pensante", por lo cual la primera podría explicar gracias a una entera racionalidad, a través del método todos los fenómenos a su alrededor. Sin embargo, para la ilustración escocesa, la relación mente-cosmos son dos caras de la misma moneda

23 Hayek entiende los fenómenos sencillos a aquellos propios de las ciencias naturales.

24 Hayek destaca el valor en este sentido de la transmisión de la experiencia: transmisión en el tiempo de nuestra acumulación de conocimiento: tradiciones e instituciones y la Comunicación de información entre contemporáneos

25 GRAY, John. F. A. Hayek y el renacimiento del liberalismo clásico. Traducido de Literature of Liberty, Vol. V, No. 4, invierno de 1982. Institute for Humane Studies, California, EE.UU. P., 8.

26 Ibíd., p., 4.

27 Ibíd.., p., 6.

28 HAYEK, Friedrich, A. Los fundamentos de la libertad. Editorial folio: Barcelona. P., 40.

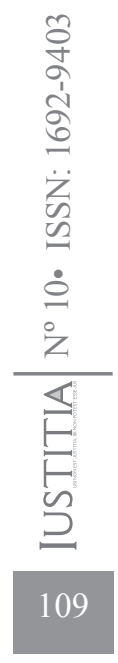


"la mente es una parte del cosmos, es decir, que la res pensante está contenida en la res extensa" por lo cual al no existir diferenciación, no puede existir objetividad y por tanto, no puede existir explicación (o auto-explicación) satisfactoria de los fenómenos de la mente. La primera tradición que emana de Descartes fundaría lo que Hayek llamó racionalismo constructivista y la segunda sería el centro del denominado racionalismo crítico $^{29}$ de influencia empirista.

La inaccesibilidad a la investigación reflexiva de las normas que regulan el pensamiento consciente trae aparejada la quiebra del proyecto racionalista cartesiano e implica que la mente humana nunca puede entenderse plenamente a sí misma; menos puede entonces, verse gobernada por cualquier proceso de pensamiento consciente. ${ }^{30}$ Este análisis hayekiano conlleva a deducir que "el orden social no pueda ser el producto de una inteligencia directriz". ${ }^{31}$

En economía la aplicación del método científico resultó en la modelización de un tipo de hombre racional, pero esta construcción no es semejante al hombre de acción, siguiendo a Mises y Hayek la idea de racionalidad plena como supuesto conductual que subyace del mecanicismo es inadecuada para explicar la realidad. Para Hayek la idea del hombre económico del positivismo científico es un error de interpretación que se realizó en el siglo XIX de las ideas de $\mathrm{Smith}^{32}$.

Los desarrollos posteriores a la economía clásica, especialmente de Walras, Jevons y Marshall al intentar "formalizar" dicho supuesto conductual, suprimiendo el papel que juega la información, el tiempo y, por tanto, la incertidumbre que implica el cálculo económico, desnaturalizan la esencia de la explicación del intercambio. En este sentido, los austriacos rechazan tanto la idea de homo oeconomicus como la noción del tiempo en la economía neoclásica.

Si bien las personas siempre están en la búsqueda de su interés individual, es decir, son egocéntricos; son racionales $^{33}$, al poder jerarquizar las opciones que tiene

29 Citando autores como G. Vico, Goethe. Hayek atribuye el verdadero individualismo al proveniente de las ideas de John Locke, Bernard Mandeville y David Hume, Josiah Tucker, Adam Ferguson y Adam Smith, Edmund Burke, Alexis de Tocqueville y Lord Acton, Carl Menger. El otro individualismo proviene, según el autor, de Bentham, John Stuart Mil, Spencer y de la influencia del pensamiento cartesiano (enciclopedistas, Rousseau, fisiócratas), el cual tiende al colectivismo y al socialismo (ingeniería social y la creencia del homo economicus). Afirma además: "no hay otra forma para llegar a una comprensión de los fenómenos sociales si no es a través de nuestro entendimiento de las acciones individuales dirigidas hacia otras personas y guiadas por un comportamiento esperado (...) es el principal responsable de la creencia en las leyes ineludibles del desarrollo histórico y del fatalismo moderno derivado"

30 GRAY. Op. Cit., p., 10.

31 Ibíd., p., 11.

32 HAYEK, Friedrich A. Individualismo: el verdadero y el falso. (1946). Trad. Revista Estudios Públicos, 22. Universidad de Chile. P., 11.

33 Pierre Cahuc explica las extensiones en la concepción del hombre que suponen la teoría microeconómica así: "el principio de racionalidad implica que los individuos utilizan de la mejor manera los recursos a su disposición, teniendo en cuenta las restricciones a las que están sujetos" CAHUC, Pierre. La nueva microeconomía. Alfaomega, Bogotá. 2001. P., 2. 
de la que le genera mayor a la que genera menor beneficio ${ }^{34}$, esto se ha reducido matemáticamente por la tendencia neoclásica ${ }^{35}$ al establecimiento de un hombre con preferencias definidas, completas (tiene la capacidad de decidir entre alternativas y nunca a dudar entre ellas) ${ }^{36}$, transitivas (capacidad de ordenar sus preferencias de manera consistente) ${ }^{37}$ y continuas ${ }^{38}$. Tales axiomas llevan a formular geométricamente el comportamiento del hombre como consumidor y como productor mediante curvas de indiferencia para determinar cómo éste, sujeto a restricciones objetivas como su capacidad adquisitiva (presupuestales), elige la canasta de bienes que optimizará su utilidad. Es de destacar que todo este funcionamiento de la "elección humana" se realiza bajo supuestos de perfecta y completa información y atemporalidad.

Mises aclara que son dos los motores de la acción humana y aunque ésta es "siempre y necesariamente racional" 39 no es infalible, puesto que los humanos se equivocan muchas veces en los medios para lograr ciertos fines, pero esto no elimina que "se trata de un método originado en una deliberación razonada (aunque defectuosa) y de un esfuerzo (si bien ineficaz) por conseguir cierto objetivo" ${ }^{\prime 40}$. Dicha deliberación sucede al percatarse el hombre de los medios que pueden originar cambios, por lo cual el ejercicio de causalidad, la inducción, es un requisito de la acción ${ }^{41}$.

En contraste, para los austriacos no constituye un problema el incumplimiento de los axiomas neoclásicos al momento de la decisión, el cambio de decisión entre alternativas (transitividad) es característico de la dinámica de la acción. Así mismo analizan la acción individual suponiendo la existencia de ignorancia y

34 El supuesto de racionalidad ha sido cuestionado además desde escuelas de tradición neoclásica hasta heterodoxas, la nueva economía institucional, la economía conductual de Daniel Kanheman, Amos Tversky y Dan Ariely. Ahora se opta por manejar el supuesto de Racionalidad limitada originario de Herbert Simons.

35 "El formalismo matemático es especialmente adecuado para recoger los estados de equilibrio que estudian los economistas neoclásicos, pero no permite incorporar la realidad subjetiva del tiempo ni mucho menos la creatividad empresarial, que son características esenciales del discurso analítico de los austriacos" HUERTA DE SOTO, Jesús. El methoden streit, o el enfoque austriaco frente al enfoque neoclásico en la ciencia económica. Capítulo I. Nuevos estudios de economía política. Pp. 21-72. Unión Editorial. P., 35.

36 NICHOLSON, 2004, 66, explica la completitud de las preferencias así: "Si A y B son dos situaciones cualesquiera, el individuo siempre puede especificar exactamente una de las tres posibilidades siguientes: A es preferida a B, B es preferida a A, o A y B son igual de atractivas. Se supone que los individuos no quedan paralizados por la indecisión: comprenden totalmente y siempre pueden decidir sobre la deseabilidad de dos alternativas cualesquiera. El supuesto también excluye la posibilidad que el individuo pueda afirmar que A es preferida a B y que B es preferida a A"

37 Si A es preferida a B y B es preferida a C, entonces A será preferida a C.

38 "Si un individuo afirma que A es preferida a B, las situaciones suficientemente "cercanas" a A también deben preferirse a B.

39 MISES. Op. Cit., p., 24.

40 Ibíd., p., 25.

41 Ibíd., p., 27. 
desinformación ${ }^{42}$, elementos que constituyen motivos en sí mismos para su la acción en un entorno de incertidumbre, puesto que ésta última incentiva el funcionamiento del mecanismo competitivo entre los agentes que llevará a mejoramientos en pro de la eficiencia vía procesos de adaptación, negando la idea de equilibrios en el sentido neoclásico, estos supuestos se conocen como homo agens. ${ }^{43}$

Por su parte, el elemento tiempo en la escuela austriaca dota de sentido a la acción humana pues es por éste que el hombre experimenta, prueba, falla y acierta, desarrolla capacidades y solventa necesidades de diversos modos las cuales traspasa a otros; este actuar no ocurre con la economía walrasiana ni marshaliana, ni en las escuelas de pensamiento económico que de éstas subyacen, pues en éstas el comportamiento económico se desarrolla atemporalmente o por lo menos en la dimensión del equilibrio, nociones totalmente ajenas a la realidad. Arguye Mises que modelar el equilibrio es tan ajeno a la acción humana puesto que es lo mismo que teorizar la inacción, es decir, un sin sentido.

\subsection{Ingeniería social ${ }^{44}$}

El producto directo del racionalismo constructivista es la pretensión de poder planear el desarrollo de la sociedad y de poder elegir los medios idóneos para los fines nobles en la sociedad. Y es claro cómo se puede llegar a tal conclusión, si se conoce cómo el hombre actúa, se pueden entonces esperar o predecir los resultados de su actuación y por esta vía intervenir mediante acciones para modificar la conducta. Esta concepción es palpable seguido Jesús Huerta de Soto, en el concepto neoclásico de economía de Lionel Robbins ${ }^{45}$ al suponer como dados los fines y los medios, la economía se convierte en un tipo de técnica u "ingeniería social” que calcula la mejor combinación en aras de la maximización ${ }^{46}$.

En esta órbita autores como Gray admiten lo absurdo que resulta la idea de que la sociedad puede desarrollarse y progresar a merced de "cualquier mente

42 Jesús Huerta de Soto afirma que cuando se habla de información en la escuela neoclásica y en la escuela austríaca se trata de dos elementos totalmente diferentes, mientras en la primera la información se refiere a "algo objetivo que, al igual que las mercancías, se compra y vende en el mercado como resultado de una decisión maximizadora", en la segunda, se refiere a "conocimiento práctico, relevante, subjetivamente interpretado, sabido y utilizado por el actor en el contexto de una acción concreta". HUERTA DE SOTO, Jesús. El methoden streit, o el enfoque austriaco frente al enfoque neoclásico en la ciencia económica. Capítulo I. Nuevos estudios de economía política. Pp. 21-72. Unión Editorial. P., 29.

43 COUYOUMDJIAN, Juan Pablo. Sobre el empresario y el emprendimiento en la teoría económica: una revisión. Disponible en sitio Web del Centro de Integración, Cooperación y Desarrollo Internacional http://www.cicodi.org/

44 Al cual arremete Mises con la siguiente frase: "Hoy suele hablarse de "ingeniería social". Este concepto, al igual que el de dirigismo, es sinónimo de dictadura, de tiranía totalitaria." MISES

45 "Economics is the science which studies human behavior as a relationship between ends and scarce means which have alternative uses" Lionel Robbins, The Nature and Significance of Economic Science $(1932,16)$.

46 HUERTA DE SOTO. Op. Cit. P., 26. 
individualmente considerada o una colectividad de mentes seleccionadas pueda hacerlo"47. Tal pretensión de la cual se deduce la idea de "cambiar las instituciones como guste" 48 es criticada vehementemente por Hayek admitiéndola como un producto del "erróneo intelectualismo para el que la razón humana es independiente de la naturaleza y posee conocimientos y capacidad de razonar independientes de la experiencia"49.

Mises además, atribuye a esta postura constructivista la idea utilitarista según la cual la sociedad y el individuo son entes en continua pugna:

"de ahí que pueda surgir un grave antagonismo entre los objetivos sociales y los individuales, lo que conduce a la necesidad de domeñar el egoísmo de los particulares para proteger la existencia y desenvolvimiento de la sociedad (...) una vez llegadas a tal conclusión, todas esas doctrinas se ven forzadas a dejar de utilizar el análisis científico y el razonamiento lógico desviándose hacia puras profesiones de fe (...)"

el abandono de la lógica y la razón para dotar de sentido las explicaciones ha llevado hasta los extremos de recurrir a la lucha armada para imponer las ideas.

Para ejemplificar lo anterior Mises reseña que la rebelión contra la razón defendida por el polilogismo marxista ${ }^{51}$ y el racista, los cuales siguen las perspectivas "objetivistas" de la explicación de los fenómenos, proponen hallar explicaciones del comportamiento humano desconociendo la estructura lógica de la mente humana y asociando su desarrollo a factores como las clases sociales en la primera o, según las razas, para el segundo caso. No obstante, tales enunciados son desmoronados por los análisis lógicos y racionales, lo cual las configura como doctrinas puramente "místicas" 52 .

No obstante, aunque tienen una misma inspiración, el primero rechaza la idea de la razón y la ciencia, mientras que el segundo se fortalece con la aceptación de dicha perspectiva, el polilogismo racista se fortalece con las teorías darwinianas de selección natural (influidas por Malthus) y de raza más acta, para sus cometidos "sociales".

En este sentido, el objeto de la economía austriaca, a diferencia de otras escuelas basadas en el determinismo científico o en el misticismo, reside precisamente en analizar los cambiantes fines y medios, a partir de los principios básicos y universales que motivan la acción humana a partir del individuo.

47 GRAY. Op. Cit. P., 11.

48 HAYEK. Los fundamentos de la libertad. Op. Cit., p., 41.

49 HAYEK. Los fundamentos de la libertad. Op. Cit., p., 42.

50 MISES.Op. Cit., p., 176.

51 "La historia de todas las sociedades que han existido hasta nuestros días es la historia de la lucha de clases.” MARX, Karl. Manifiesto del partido comunista. Editores Unidos.

52 MISES. Op. Cit., p., 96. 
Según Huerta de Soto el individuo en la sociedad "lo que realmente hace es buscar constantemente nuevos fines y medios, aprendiendo del pasado y usando su imaginación para descubrir y crear (mediante la acción) el futuro"53. Desde la perspectiva de Hayek "todo aquello a lo que la ciencia puede aspirar es a una explicación del principio o al reconocimiento de un esquema, la explicación no de los hechos individuales sino meramente de la aparición de ciertos esquemas u órdenes" 54 .

La pretensión metodológica de las ciencias sociales debe ser utilizar la deducción en la forma ${ }^{55}$ y la inducción en el "contenido". Las deudas de Hayek con Popper consisten, entonces, en haber considerado que es la posibilidad de falsificación de una hipótesis y no su posibilidad de verificación ${ }^{56}$ lo que la hace contrastable y empírica y, en segundo lugar, en reconocer la unidad del método en todas las ciencias, naturales y sociales, donde se observa que este método es claramente hipotético-deductivo. En este sentido, la teoría económica austriaca pretende “(...) describir tipos de modelos que surgirán si se satisfacen ciertas condiciones generales, pero difícilmente, si es que alguna vez, puede derivar de este conocimiento alguna predicción de fenómenos específicos". ${ }^{57}$

La predicción de hechos y comportamientos, así como el diseño de mecanismos y de instituciones para moldear resultados, son métodos en contra del mismo progreso humano. Hayek hace un llamado a entender el progreso "como un proceso de formación y modificación del intelecto humano; un proceso de adaptación y aprendizaje en el cual no sólo las posibilidades conocidas por nosotros, sino también nuestros valores y deseos, cambian continuamente" ${ }^{58}$. El papel de la ciencia social se debe centrar en este sentido en comprender, analizar y deducir: "la razón humana no puede predecir ni dar forma a su propio futuro. Sus progresos consisten en encontrar dónde estaba el error." 59

Este proceso de formación y de modificación gradual depende de las valoraciones individuales, el progreso humano nunca se dará de forma igualitaria y absoluta, y esta idea se puede denotar claramente en el terreno de los adelantos tecnológicos, puesto que siempre serán unos los primeros en gozar del ingenio del individuo, mediante ensayo y error, para después todos gozar de dichas innovaciones. En esta órbita, Hayek establece que los descubrimientos “(...) tienen que pasar a través de un dilatado proceso de adaptación, selección, combinación y mejoramiento antes que se puedan utilizar por completo. Esto significa que siempre existirán gentes que se beneficien de las nuevas conquistas con antelación al resto de los mortales" ${ }^{90}$, por lo cual, la desigualdad es inherente a los procesos que emergen de la acción humana: “en principio, un nuevo bien o mercancía, antes de llegar a ser una necesidad pública

53 HUERTA DE SOTO. Op., Cit., p., 27.

54 GRAY. Op., Cit., p., 16.

55 GRAY. Op., Cit., p., 17.

56 De lo contrario cualquier relación o asociación es posible someter a verificación.

57 Ibíd., p., 117.

58 Ibíd., p., 60.

$114 \quad 59$ Ibídem.

60 Ibíd., p., 62. 
y formar parte de las necesidades de la vida, constituye generalmente el capricho de unos pocos escogidos". ${ }^{61}$

Sobre el debate entre el empirismo y el racionalismo constructivista y el subyacente método de investigación de cada uno, Hayek concluye que la primera doctrina "encuentra la esencia de la libertad en la espontaneidad y en la ausencia de coacción (...) a favor del método de la prueba y el error” natural de la acción humana, en cambio, el segundo se basa "sólo en la persecución y consecución de un propósito colectivo absoluto (...) en pro de un patrón obligatorio válido para todos"62, al cual todos deben converger.

Siguiendo la primera, también recae una crítica al llamado darwinismo social de la segunda, puesto que la evolución de las sociedades no se asemeja al proceso de selección natural:

"En la evolución social, el factor decisivo no es la selección mediante la imitación de instrumentos y hábitos que tienen éxito. Aunque opere también a través del éxito de individuos, sino las ideas y conocimientos prácticos; para abreviar, la total herencia cultural que pasa de unos a otros mediante el aprendizaje y la imitación"63

Hayek acude al argumento del uso del conocimiento en la sociedad, puesto que la información y los conocimientos se hallan es en los individuos y en su libre interactuar y en el día a día tomar decisiones y sopesar sus acciones, no en una o en un grupo de mentes, un mecanismo que pretenda dirigir dicho esfuerzo terminará por limitar al ser humano a potencializar sus capacidades, impedir el desarrollo de nuevos medios para alcanzar nuevos fines, en últimas se llegaría al estancamiento de la sociedad. Hayek arguye:

"si la fuente de todas las voliciones, valoraciones y conocimientos se encuentra
en la capacidad creativa y empresarial del ser humano, todo sistema que se
base en el ejercicio de la coacción violenta contra el libre actuar humano,
como es el caso del socialismo, impedirá la creación y transmisión de la
información necesaria para coordinar la sociedad."

En conclusión las premisas de Mises y Hayek, en contra del positivismo científico en la economía, apuntan a confiar en los individuos como gestores de su bienestar, puesto que en ese proceso se posibilitan la creación de medios efectivos para el desarrollo de los fines deseables por ellos. Entre estos medios se encuentran las instituciones que dan orden y establecen límite a la acción humana o que simplemente facilitan su progreso.

61 HAYEK, F., A. Fundamentos de la libertad. Op. Cit., p., 63.

62 HAYEK, F., A. Fundamentos de la libertad. Op. Cit., p, 76.

63 HAYEK, F., A. Fundamentos de la libertad. Op. Cit., p, 80.

64 HUERTA DE SOTO. Op Cit., p., 49. 


\subsection{Abandono de otras disciplinas}

A diferencia del concepto estándar de la economía en los neoclásicos, los austriacos entienden la economía como una parte de una ciencia humana general e integral denominada praxeología o ciencia de la acción humana. Por tanto, su análisis no se remite exclusivamente a una faceta de dicha acción (económica, jurídica, política), como lo forjó la visión cartesiana, sino que la trata en el marco de un conjunto de supuestos o axiomas generales. Además se ha señalado que la definición de Robbins conlleva a que la economía constituya la ciencia de la elección más no de la acción humana como pretenden los austriacos.

La aplicación del método científico a la economía, la subsecuente aplicación de las matemáticas y de las diversas técnicas estadísticas (especialmente la econometría) para explicar fenómenos estrictamente económicos que identifica en ellos ciertas regularidades empíricas, separó a la disciplina de otras que en conjunto denotan la naturaleza de la acción en sociedad. Así, la acción es resultado de un cúmulo de factores económicos, sociales, políticos, morales, históricos, entre otros, que no es posible separar.

Otro de los errores de la disciplina económica, que aún se evidencia internamente, es la distinción entre micro y macro economía, puesto que si bien las dos corresponden al objetivismo y determinismo impregnado en la ciencia, la segunda acude a caracterizar y contabilizar la vida económica de conglomerados. Según Mises, tales conceptualizaciones
"siguen anclados en la etapa pre-científica de la economía en la que el análisis aún se intentaba efectuar en términos de clases globales o agregados de bienes, más que en términos de unidades incrementales o marginales de los mismos. Esto explica por qué se ha desarrollado toda una «disciplina» basada en el estudio de las supuestas relaciones mecánicas existentes entre agregados macroeconómicos cuya conexión con la acción humana es muy difícil, si no imposible, de entender. ${ }^{65}$

Pero las relaciones económicas, no son una pieza de la acción humana, son el resultado de dicha acción, la cual no se desata de la influencia de las instituciones, de la historia, de las tradiciones, elemento que pretendió olvidar con la atomización. Uno de los primeros distanciamientos que produjo dicha concepción fue la separación de la economía del derecho, lo cual dota de incompletitud al análisis económico, pues son las instituciones las que determinan la forma del intercambio (lo potencia o lo debilitan en palabras de Cachanosky) y, por tanto, del funcionamiento del mercado. En tal ámbito, señala Juan Cachanosky los austriacos "continuaron desarrollando tanto la teoría económica como el marco legal y político que potencia o disminuye los beneficios del mercado"66. 
Así mismo, Mises defiende que no existe independencia entre el aspecto político y aspecto económico: "el ser humano no tiene por un lado una faceta económica $\mathrm{y}$, por el otro, una faceta política sin ninguna conexión entre ambas (...). Los acontecimientos políticos son la inevitable consecuencia del cambio en las políticas económicas." ${ }^{67}$ Además que las ideas políticas emergen del mismo desarrollo y evolución de la sociedad, de los cambiantes fines y medios.

\section{LA ESCUELA AUSTRIACA: IMPLICACIONES METODOLÓGICAS PARA EL ESTUDIO DE LA ECONOMÍA}

\subsection{La acción humana como objeto de estudio}

Ante los desaciertos en la fundamentación de la teoría económica, desde el punto de vista austriaco, Mises propone el estudio de una nueva ciencia "teórica y sistemática"68 denominada por él praxeología, cuyo objeto de estudio radica en la acción humana tal como es, desde herramientas propias de la razón, como la lógica, que permita deducir los principios ordenadores de dicha acción y los efectos de la misma en la sociedad, ante esto Mises señala:

"Sus enseñanzas son de orden puramente formal y general, ajenas al contenido material y las condiciones peculiares del caso de que se trate. Aspira a formular teorías que resulten válidas en cualquier caso en el que efectivamente concurran aquellas circunstancias implicitas en sus supuestos y construcciones. Sus afirmaciones y proposiciones no derivan del conocimiento experimental (...) son a priori" ${ }^{\prime}$.

Todo lo anterior tenida en cuenta la naturaleza de la capacidad cognitiva70 para efectuar la acción, no pretende encontrar explicaciones empíricas para los fenómenos, regularidades, ni aproximaciones cuantitativas. Por lo cual, su método no recurre a "experimentos de laboratorio ni en el conocimiento sensorial de la realidad externa (...). Lo único que se precisa confirmar es si los presupuestos de la construcción coinciden con las condiciones de las acciones que se quiere enjuiciar."71, tal método se conoce como apriorístico o lógico-deductivo. A diferencia de la metodología

67 MISES, LUDWING. Política económica. Pensamientos para el hoy y mañana. Buenos Aires: Editorial El ateneo. 1993. P., 88.

68 MISES. La acción humana. Op. Cit. p., 39. Aclaración que realiza Mises en contraposición a las ciencias históricas que se encargan de estudiar hechos del pasado, sistematizándolos y manipulándolos de tal manera que se encuentren ciertas regularidades empíricas.

69 MISES. La acción humana. Op. Cit. p., 39.

70 Es de destacar en este sentido, el avance de Hayek en la psicología teórica, especialmente en el libro: HAYEK, Friedrich A. El Orden sensorial. Los fundamentos de la psicología teórica. Unión Editorial.

71 MISES. La acción humana. Op. Cit. p., 289 
tradicional la escuela austriaca pretende avanzar en concebir y comprender "el significado de las acciones económicas"72, de “(...) descubrir el sentido y la trascendencia de las distintas actuaciones" 73 admitida la existencia de conocimiento a priori y despreciadas las bondades de la observación y experimentación. Un método de este tipo es totalmente desconocido en la percepción tradicional y dominante de la ciencia económica actual impregnada de la visión cartesiana.

Después de la comprensión de dicho conocimiento se remite a la deducción, el método de la praxeología recurre a lo que denomina Mises "las construcciones imaginarias" según la cual corresponde a "una imagen conceptual de una consecuencia de hechos que se desarrollan lógicamente a partir de los elementos de la acción empleada en su realización. Es fruto por tanto de la deducción, derivando por eso de la categoría fundamental del actuar, es decir, del preferir y rechazar." 74

El método consiste en la abstracción de la acción y los elementos que la condicionan en un determinado ámbito e identificar: "las consecuencias hipotéticas de la ausencia de estas condiciones y concebir los efectos de su existencia." ${ }^{\text {. }}$.

\subsection{Acción humana a partir del individuo}

Al igual que la economía estándar parten del individuo como centro de interés, puesto que quien protagoniza la acción, "siempre es el individuo quien piensa"76 y el que la dota de contenido (fines y medios que dependen de las condiciones particulares $^{77}$ de cada uno $^{78}$ ), el que posee la información sobre sus particulares condiciones. Bajo estos supuestos se pretender llegar a conocer "la esencia de las múltiples acciones individuales, por fuerza habremos aprehendido todo lo relativo a la actuación de las colectividades." ${ }^{.9}$.

En este sentido, es preciso destacar cómo desde la praxeología se ha intentado explicar el funcionamiento del mercado o de los intercambios individuales, la denominada cataláctica $^{80}$, desde dos ópticas hipotéticas extremas: la existencia del mercado desprendido de la acción individual y la no-existencia del mercado, es decir,

72 LACHMANN, Ludwig. El significado de la escuela austríaca de economía en la historia de las ideas. Revista Libertas 27. Octubre 1997. Instituto Universitario ESEADE www.eseade.edu.ar.

73 Ibíd., p., 62.

74 MISES. La acción humana. Op. Cit. p., 288.

75 Ibíd., p.,2 89.

76 Ibíd., p., 213.

77 Entre las que destaca la herencia y el entorno.

78 Ibíd., p., 55.

79 Ibíd., p., 51.

80 Hayek expresa sobre tal denominación: “(...) la teoría que explica el funcionamiento del mercado se ha denominado cataláctica, del griego clásico, kata lattein, término que significa, transar o intercambiar. Me he enamorado de esta palabra desde que descubrí que en el griego antiguo ésta significaba, además de "intercambiar", "admitir dentro de la comunidad" y "cambiar de enemigo en amigo". He propuesto, por lo tanto, que llamemos al juego de mercado, a través del cual podemos inducir al forastero a acogernos y servirnos, el "juego de catalaxia". HAYEK, Friedrich. El atavismo de la justicia social. 
del socialismo, a partir de las categorías praxelógicas universales de la acción ${ }^{81}$.

No obstante, este estudio del mercado a partir del individuo no guarda correspondencia alguna con la creación determinista del homo oeconomicus ${ }^{82}$, tal como afirma Mises: “(...) ese homo oeconomicustal vez sirva para retratar a los especuladores y a jugadores de bolsa; pero la gente, en su inmensa mayoría, es bien diferente. El estudio de la conducta de ese ser imaginario de nada sirve cuando lo que se pretende es aprehender la realidad tal como es" 83 .

Se parte del supuesto conductual según el cual dicho individuo es motivado por sus intereses personales, el tradicional egoísmo: "El hombre actúa siempre para acrecentar su satisfacción personal. En este sentido -y en ningún otro- cabe emplear el término egoísmo y decir que la acción es siempre y necesariamente egoísta" ${ }^{84}$. Esta característica implica que el individuo actúe de tal modo que permita mejorar siempre o maximizar su bienestar. Por lo cual se deduce que la acción humana es producto de la propensión del hombre a mejorar su situación:

Axioma central: "la acción humana implica el intento deliberado de pasar de una situación menos satisfactoria a otra más satisfactoria" ${ }^{95}$

Mises define la acción humana como

"una conducta consciente, movilizada voluntad transformada en actuación, que pretende alcanzar precisos fines y objetivos; es una reacción consciente del ego ante los estímulos y las circunstancias del ambiente; es una reflexiva acomodación a aquella disposición del universo que está influyendo en la vida del sujeto." " "La acción no consiste en simplemente preferir (...) quien solo desea y espera no interviene activamente en el curso de los acontecimientos ni en la plasmación de su destino. El hombre, en cambio, al actuar, opta, determina y procura alcanzar un fin. De las dos cosas que no pueda disfrutar al tiempo, elige una y rechaza la otra. La acción, por tanto, implica, siempre y a la vez, preferir y renunciar." ${ }^{\text {" } 7}$

81 "Partiendo de tales presupuestos, la economía trata de averiguar los efectos de semejante organización. Solo más tarde, cuando ya ha quedado debidamente expuesto cuanto se puede inferir del análisis de esa construcción imaginaria, para el economista a examinar las cuestiones que suscita la interferencia del gobierno o de otras organizaciones capaces de recurrir a la fuerza y a la intimidación en el funcionamiento del mercado". MISES. La acción humana. Op. Cit., p., 290.

82 Hayek aduce que "Quizá la mejor ilustración de las malas interpretaciones del individualismo de Adam Smith y su grupo sea la creencia común que ellos inventaron el fantasma del "hombre económico" y que sus conclusiones están viciadas por su suposición de un comportamiento estrictamente racional o generalmente por una falsa sicología racionalista." HAYEK, Friedrich. Individualismo: el verdadero y el falso P., 11.

83 Ibíd., p., 292.

84 Ibíd., p., 295.

85 ZANOTTI, Gabriel. Fundamentos filosóficos y epistemológicos de la praxeología. Tesis de 1990 para optar por el título de doctor en Filosofía [edición 2002]. Acto Institute. P., 17

86 MISES. Op. Cit., p., 15

87 Ibíd., p., 17 
La propensión del hombre a procurarse bienestar y a mejorar como primer requisito y axioma central de la acción está motivada por un proceso de razonamiento: “(...) La mente presenta al actor situaciones más gratas, que éste, mediante la acción, pretende alcanzar. Es siempre el malestar el incentivo que induce al individuo a actuar.”. No obstante, recalca Mises que ninguna de las dos (propensión a mejorar y a superar el malestar) son por sí solas razones suficientes para el actuar, es necesario un tercer requisito, "advertir mentalmente la existencia de cierta conducta deliberada capaz de suprimir o, al menos, de reducir la incomodidad sentida." ${ }^{88}$, es decir, el hombre necesita, planea y decide entre medios para alcanzar de mejor forma sus fines.

Según Mises el resultado que la acción persigue se llama su fin, y los medios corresponden a todo cuanto sirve para lograr cualquier fin" 89 . En este sentido, "fin es cuanto el hombre apetece; medio, cuanto el actor considera tal"90. Así mismo, los fines "son datos irreductibles, son puramente subjetivos, difieren de persona a persona y, aún en un mismo individuo, varían según el momento." ${ }^{11}$. De aquí subyace lo contraproducente que puede ser la planeación de la vida por una sola mente.

Recalca Mises el carácter subjetivo también de los medios, puesto que tales medios no existen per se, sólo existen cosas que por medio de la razón se conoce su utilidad para satisfacer necesidades humanas, estos medios a la vez resultan siempre escasos $^{92}$, como todos los bienes económicos.

Siguiendo a Menger, los bienes entonces se clasifican según su cercanía a la satisfacción de necesidades, es decir a la utilidad que genera en el individuo, en este sentido, establece la caracterización de bienes de primer orden (o de consumo) son aquellos medios que directamente por sí solos, sirven para satisfacer necesidades humanas; bienes de segundo orden o de producción más próximos al artículo de consumo y; bienes de tercer orden remitiéndose a aquellos empleados para la producción de los bienes de segundo orden. ${ }^{93}$

En esta órbita el valor de todos los bienes está determinado por los bienes de primer orden, los más cercanos a la provisión de satisfacción, por lo cual, se deduce que el valor consiste en un elemento subjetivo, o "metafórico" como señalábamos atrás, asociado a “(...) la importancia que el hombre, al actuar, atribuye a los fines últimos que él mismo se haya propuesto alcanzar." ${ }^{4}$

No existe tampoco una medida para las necesidades, éstas depende de la valoración subjetiva de cada uno demostrada en el ordenamiento, la elección y la acción humana. Sólo mediante la acción voluntaria el hombre experimenta el cambio

92 Escasez relativa: "los medios resultan siempre escasos, es decir, insuficientes para alcanzar todos los objetivos a los que el hombre aspira. De no ser así, la acción humana se desentendería de ellos. El actuar, si el hombre no se viera inexorablemente cercado por la escasez, carecería de objeto". MISES, p., 112

93 Ibíd., p., 113

94 Ibíd., pp., 115-116 
en sus condiciones de vida, la acción al sustituir un estado de malestar (o poco satisfactorio) por uno satisfactorio provoca y evidencia el cambio, dicha renuncia (de elección entre $A$ y $B$ ) es indicador del costo y es precisamente la raíz del concepto costos austriaco, conocido como costo de oportunidad o costo subjetivo:
“(...). Aquello a lo que es preciso renunciar para alcanzar el objeto deseado constituye el precio pagado por éste. El valor de ese precio pagado se llama costo. El costo es igual al valor que se atribuye a la satisfacción de la que es preciso privarse para conseguir el fin propuesto." 95

Por su parte, los beneficios constituyen la diferencia de valor o de satisfacción entre el precio pagado y el precio de la meta alcanzada (incremento de satisfacción). Cuando la acción produce una situación peor "la diferencia entre el valor del costo y el del resultado obtenido la denominamos pérdida."96

Tal carácter subjetivo de valor en palabras de Mises radica en "consideraciones metafísicas, religiosas y éticas, juicios de valor estético, costumbres, hábitos, prejuicios, tradiciones, modas y otras mil circunstancias" ${ }^{\prime 97}$ diferentes en cada caso.

“(...). El juicio de valor no mide, se limita a ordenar en escala gradual; antepone unas cosas a otras. El valor no se expresa mediante peso ni medida, sino que se formula a través de un orden de preferencias y secuencias. En el mundo del valor sólo son aplicables los números ordinales; nunca los cardinales." 98

Al valorar el hombre ordena de acuerdo a la idoneidad y oportunidad de los medios para procurar satisfacción de sus necesidades, es decir según su utilidad: "Quien actúa no ve más que cosas, cosas de diversa utilidad para su personal bienestar, cosas que, por tanto, desea con distinta intensidad"99. Por tanto, para la praxeología y como para la cataláctica, el concepto de utilidad “(...) equivale a la importancia atribuida a cierta cosa en razón a su supuesta capacidad para suprimir determinada incomodidad humana"100.

Si bien la metodología austriaca es formal y lógica, por lo cual no tendría cabida categorías de tiempo, ni de causa-efecto, esto no implica que se excluyan dichas categorías en el análisis de la acción puesto que la lógica de la acción surge en el espacio y en el tiempo, es decir lo que se trata en primer lugar es de determinar coherencia praxeológica (es decir, la constancia o adhesión a unos mismos principios). Dado que "la acción sólo puede ser constante en un sentido: en preferir lo de mayor a lo de menor valor" 101 pero esta constancia se enmarca en un entorno temporal por lo cual genera incertidumbre y riesgo y dada las premisas fundamentales de la acción convierten al hombre en un especulador. En este ámbito, en análisis lógico se dota de sentido, afirma Mises: 
"(...) en el mundo real el hombre que actúa se enfrenta con el hecho de que hay otros que, como él, operan por sí y para sí. La necesidad de acomodar la propia actuación a la de terceros concede al sujeto investidura de especulador. $\mathrm{Su}$ éxito o fracaso dependerá de la mayor o menor habilidad que tenga para prever el futuro. Toda acción viene a ser una especulación. En el curso de los acontecimientos humanos nunca hay estabilidad ni, por consiguiente, seguridad." 102

La acción en la sociedad implica necesariamente ${ }^{103}$ la cooperación humana, la propensión o natural disposición a mejorar del hombre (alcanzar fines) lo lleva a recurrir a los demás para satisfacer los deseos, y esta concurrencia origina la división del trabajo ${ }^{104}$. En este sentido, surge la mutualidad de la mano invisible de Smith, el sujeto sirve a los demás con miras a ser en cambio servido por terceros. ${ }^{105}$ Tal tipo de cooperación lleva a un tipo de coordinación voluntaria en la sociedad, señala mises, o en virtud del contrato está inherente en el actuar humano, esto sería llamado por Hayek como orden espontáneo. De acuerdo a esta cooperación necesaria para el alcance de fines humanos Hayek contrasta con el imperativo categórico kantiano para asumir que en este contexto el hombre es fin y medio al mismo tiempo, idea también trabajada por Mises en su tratado aduciendo:

"La economía de mercado es un sistema social de división de trabajo basado en la propiedad privada de los medios de producción. Cada uno, dentro de tal orden, actúa según le aconseja su propio interés; todos, sin embargo, satisfacen necesidades de los demás al atender las propias (...) el hombre es al mismo tiempo medio y fin; fin último para sí mismo y medio en cuanto coadyuva con los demás para que puedan alcanzar sus propios fines."106

No obstante, a través de la historia se ha dado otro tipo cooperación en virtud del mando y la subordinación, "hegemónica"107, no fundada en simetría y reciprocidad como en la primera y que cohíbe la evolución humana.

El cálculo económico es, entonces, un proceso inherente a dicha cooperación humana y es el instrumento de planeación de la acción por los individuos (descentralizada), dicho cálculo motivado por la valoración subjetiva se expresa en los precios monetarios ${ }^{108}$ que son en última los informadores y coordinadores

102 Ibíd., p., 137.

103 Cuando no se realiza el intercambio interpersonal se da el llamado intercambio intrapersonal o "autístico" solo evidente en épocas primitivas o en el metafórico Robinson Crusoe.

104 "Los dos hechos fundamentales que originan la cooperación (...) son, de un lado, el que la labor realizada bajo el signo de la división del trabajo resulta más fecunda que la practicada bajo un régimen de aislamiento y, de otro, el que la inteligencia humana es capaz de reconocer esta verdad." MISES, P., 174.

105 Ibíd., p., 233.

106 Ibíd., p., 313

107 Ibíd., p., 234.

108 “El cálculo económico puede referirse a todo cuanto se cambia por dinero". MISES, Ludwing. La acción humana. P., 257. 
de la sociedad. Para Mises, el cálculo económico ha sido un continuo error ${ }^{109}$ en la economía al asociarlo con elementos objetivos y dejando de lado las especiales condiciones de tiempo, información y demás.

Las teorías sobre los precios parten de la concepción objetiva del valor de los bienes que data desde los clásicos, los bienes poseen un valor intrínseco conlleva entonces a que tal pueda ser medido, si podemos establecer la medida exacta de tales podemos así mismo intervenir para variar su valor.

El proceso de cálculo económico asimismo es el que fomenta las capacidades empresariales en los individuos al decidir entre medios y fines, también elige entre medios para satisfacer necesidades inmediatas y las futuras y por tanto a decidir entre invertir y consumir. El cálculo económico de la inversión resulta de "La suma resultante de valorar en términos monetarios el conjunto de bienes destinados a inversiones -el capital- constituye el punto de partida de todo cálculo económico" 110 . La inversión depende a su vez del consumo, la ganancia y el ahorro que se puede obtener.

En cuanto a esto, Mises ratifica que "en el terreno praxeológico y económico (...), carece de sentido toda idea de medición" 111 y es precisamente esta idea contraria a la del cálculo económico individual, es decir la de cálculo económico agregado o centralizado (precios, riqueza, beneficios sociales), la que ha fomentado todo un tecnicismo a favor de regímenes autoritarios, centralistas y planificadores (el famoso Estado de Bienestar), los cuales pretenden por medio del uso de dichas herramientas proveer la justa medida de medios para alcanzar ciertos fines colectivos, considerados deseables (ingeniería social).

Los críticos del capitalismo “(...) eluden cuidadosamente el problema del cálculo económico, lo cual les impide advertir las consecuencias que la ausencia del mismo provoca necesariamente" 112 , es precisamente el conocimiento, la información dispersa en cada uno de los miles de individuos que conforma el mercado la que permite realizar el cálculo económico y este, a su vez, determinar los precios de los bienes y proveer los datos e información necesaria para la coordinación y posterior cálculo, los precios actúan como coordinador, en este argumento radica la imposibilidad del cálculo socialista. En una economía centralizada o socialista los precios los instauraría un individuo calculador, autoridad central o ingeniero social no puede obtener dicho conocimiento disperso ${ }^{113}$.

109 "La elaboración de la ciencia económica depende heurísticamente en tal medida del proceso lógico de cálculo que los economistas han sido incapaces de plantear correctamente el fundamental problema que implican los métodos del cálculo económico.” Ibíd., p., 244.

110 Ibíd., pp. 317-318

111 Ibíd., p., 269.

112 Ibíd., p., 323

113 HAYEK, Friedrich A. Dos páginas de ficción. [1982]. Traducción publicada por Estudios Públicos No. 10 . 


\subsection{Consideraciones políticas}

La acción humana como objeto de estudio merece una perspectiva integrada, para esto es necesario realizar un análisis conjunto de las instituciones y de los sistemas políticos alrededor de ella desde las categorías de la acción. En este sentido, es clara la aportación de Hayek en teoría social, política, económica y psicológica.

Hayek sería un reformulador de las ideas liberales que fomentaron el Estado liberal y también de las fallas inmersas en dichas ideas que no permitieron su desarrollo satisfactorio desde un análisis praxeológico demuestra la oportunidad de las instituciones creadas espontáneamente para procurar ordenes sociales.

En contraste Mises afirmar que la teoría praxeológica si bien permite interpretar los fenómenos humanos, la cataláctica los referidos al mercado y al cálculo monetario, también bajo el primer ejercicio puede permite recomendar los medios ${ }^{114}$ garantizar el mejor desarrollo de la acción. Por lo cual, del terreno estrictamente descriptivo pasan al terreno político, pero sin cercenarlo de evidencia praxeológica, propia de la comprensión de los fenómenos sociales.

Desde tal órbita en el plano político y jurídico argumentan que las instituciones de la propiedad privada y de la libertad, creación que el hombre con base a su experiencia, la forma idónea de poder desarrollar la acción. En tal línea, Mises señala: "aunque la libertad no es un estado de la naturaleza, sino una creación de la civilización, no surge de algo intencionalmente"115

Así, Hayek siguiendo la tradición racionalista crítica entiende el origen de las instituciones en el aprendizaje humano, por lo cual señala que éstas son: "producto de la acción humana pero no del diseño humano", dado que "han tenido una evolución dilatada en el tiempo, siguiendo procesos de imitación y de ensayo y error"116. Postura contraria a la defendida por el racionalismo francés, constructivista, para el cual su origen se remite a creación deliberada del hombre.

De la primera postura subyace la idea de "orden espontáneo" ${ }^{117} \mathrm{y}$, por tanto, de democracia liberal, mientras que de la segunda ${ }^{118}$ se deduce que se encuentra "el más alto grado de civilización política en la organización, es decir, en el más alto grado de intervención estatal" ${ }^{119}$ y por tanto de democracia social.

En este sentido, Hayek argumenta la defensa de la institución de la libertad como producto de dicha evolución y señala, entre otras, que las principales razones a favor de la libertad en este ámbito, están dadas por "nuestra inevitable ignorancia

114 "Una concepción del mundo es, en cuanto a teoría, una interpretación global de todos los fenómenos y, en cuanto a norma rectora de la acción, un opinión acerca de los medios más idóneos para suprimir la incomodidad en la mayor medida posible.” MISES., La acción humana. p., 214

115 HAYEK. Los fundamentos de la libertad. Op. Cit., p. 73

116 ORTOZ, David. El orden sensorial, individualismo y conocimiento económico en la obra de F. A. HAYEK. Rev.econ.inst. Vol.11, (20). Bogotá, Junio 2009.

117 Defendida entre otros por el empirismo inglés de David Hume, Adam Smith, Adam Ferguson, Josiah Tucker, Edmund Burke, Willam Paley. Ejemplo: jurisprudencia del common law.

118 Propia de enciclopedistas, Rousseau, fisiócratas, Condorcet.

119 HAYEK.. Los fundamentos de la libertad. Op. Cit., p., 74. 
de muchos de los factores que fundamentan el logro de nuestros fines y bienestar" ${ }^{\prime 20}$ (...) y afirma la nocividad de la fatal arrogancia al pretender planear lo que de forma espontánea y natural se desarrolla: "aunque ello sea humillar la soberbia humana, debemos reconocer que el desarrollo e incluso la conservación de la civilización depende en gran medida de la oportunidad de que ocurran casualidades"121.

Así mismo manifiesta que la libertad es la mejor forma de aprovechar el conocimiento disperso entre los individuos en la sociedad, cuando afirma: "debido a que la libertad significa la renuncia al control directo de los esfuerzos individuales, la sociedad libre puede hacer uso de mucho más conocimiento del que la mente del más sabio de los legisladores pudiera abarcar"122. Incluso debe prevalecer la libertad aun "cuando el uso que algunos hacen de ella no nos parece deseable" puesto que sin ésta "nunca lograríamos los beneficios de ser libres; nunca obtendríamos esos imprevisibles nuevos desarrollos cuya oportunidad la libertad nos brinda" ${ }^{123}$.

En el campo político la posición de Hayek y en coherencia con las premisas estudiadas

“(...) aunque pueda haber una política lícita con respecto a las instituciones económicas, no puede haber algo como la política económica tal como en este momento se la entiende, porque someterse al Estado de derecho excluye todo lo que se parezca a un manejo macroeconómico. ${ }^{124}$

Para Hayek y Mises el liberalismo de siglo XIX no llegó a su plenitud ${ }^{125}$ y aún así cambió el designio del desarrollo humano, entre sus barreras se destacan el tratado cientificismo combinado con modos de pensamiento colectivistas que olvidan la individualidad por objetivos gaseosos de la colectividad. El reconocimiento de Hayek de que el funcionamiento del mercado depende de las instituciones dotadas de herramientas para resucitar aquella rama del saber llamada economía política.

\section{REFLEXIÓN FINAL}

El desarrollo del cientificismo en la economía ha llevado a convertirla en un tipo de tecnicismo para la asignación de medios dados a fines también determinados ex ante. Ante esto el estudio ha suprimido la esencia del análisis del intercambio humano, sus motivaciones, implicaciones y efectos. Ese enfoque ha dado cuenta de diversas formas que pretender manejar la economía o controlar el desarrollo de los intereses egoístas, lo cual recae en falsas concepciones objetivistas de la realidad.

El reduccionismo y tecnicismo subyacente ha dotado a la economía de un estatus de ciencia, en el sentido del denominado por Hayek racionalismo constructivista,

120 Ibíd., p. 47.

121 Ibíd., p. 48.

122 Ibíd., p., 50.

123 Ibíd., p., 50

124 GRAY. Op. Cit., p., 18.

125 MISES, Ludwing. Sobre liberalismo y capitalismo. Tomo I. Folio, biblioteca de economía. Unión Editorial S.A., Barcelona. [Traducción Joaquín Reig Albiol]. 1996. 
con la pretensión de hallar las causas objetivas de los fenómenos e identificar regularidades empíricas en los mismos que permitan intervenir efectivamente. Si bien esta perspectiva ha ganado en explicaciones y teorizaciones ha perdido en posibilidad de comprensión de fenómenos desde una perspectiva realista y, por tanto, de ejercer el papel oportuno en el desarrollo social.

El método estándar de la economía si bien surgió del atomismo cartesiano hoy es aplicado a una infinidad de análisis de la conducta humana no motivada por elementos estrictamente de mercado. En esta órbita proliferan los análisis económicos aplicados al derecho, la psicología, la sociología y la política entre otros, tomando como base los supuestos conductuales que caracterizar al homo oeconomicus y los supuestos de racionalidad e información propios de un análisis de equilibrio. Aunque de varias vertientes han surgido críticas a dicho método se conserva elementos básicos del análisis estándar lo cual no provee una perspectiva amplia y real de los fenómenos.

La economía política de los clásicos debe ser retomada e insertar nuevos elementos de análisis que permitan sustituir el método cartesiano, el objetivismo y sus productos: la ingeniería social, por métodos comprensivos con perspectivas integrales del ser y la capacidad de raciocinio humano.

\section{REFERENCIAS}

BONESSANA, Cessare. Tratados de los delitos y las penas. 1764. (Edición de 1993). Argentina: Editorial Heliasta.

CACHANOSKY, Juan C. Economía, Derecho y el "Análisis económico del Derecho".

CACHANOSKY, Juan C. Historia de las teorías del valor y el precio. Revista Libertas 22. Mayo 1995. Instituto Universitario ESEADE www.eseade.edu.ar

CACHANOSKY, Juan C. La escuela austriaca de economía. S.f. P., 11. Disponible en sitio Web http://www.hacer.org/

CAHUC, Pierre. La nueva microeconomía. Alfaomega, Bogotá. 2001.

COUYOUMDJIAN, Juan Pablo. Sobre el empresario y el emprendimiento en la teoría económica: una revisión. Disponible en sitio web del Centro de Integración, Cooperación y Desarrollo Internacional http://www.cicodi.org/

DESCARTES, Renato. El discurso del método.

GRAY, John. F. A. Hayek y el renacimiento del liberalismo clásico. Traducido de Literature of Liberty, Vol. V, No. 4, invierno de 1982. Institute for Humane Studies, California, EE.UU.

HAYEK, Friedrich A. Dos páginas de ficción. [1982]. Traducción publicada por Estudios Públicos No. 10.

HAYEK, Friedrich A. La teoría de los fenómenos complejos [Traducción]. Editado por M. Bunge, y publicado por MacMillan Publishing Co., Inc. (1964). Revista Estudios Públicos. Chile. 
HAYEK, Friedrich A. Individualismo: el verdadero y el falso. [1946]. Trad. Revista Estudios Públicos, 22. Universidad de Chile.

HAYEK, Friedrich, A. Los fundamentos de la libertad. Editorial folio: Barcelona. 1960.

HAYEK, Friedrich. El atavismo de la justicia social. Traducción en Revista Estudios Públicos. Chile. 1977.

HUERTA DE SOTO, Jesús. El methoden streit, o el enfoque austriaco frente al enfoque neoclásico en la ciencia económica. Capítulo I. Nuevos estudios de economía política. Pp. 21-72. Unión Editorial.

LACHMANN, Ludwig. El significado de la escuela austríaca de economía en la historia de las ideas. Revista Libertas 27. Octubre 1997. Instituto Universitario ESEADE www.eseade. edu.ar.

MARX, Karl. Manifiesto del partido comunista. Editores Unidos.

MENGER, Carl. Principios de economía política. 1871. [Edición disponible en Web].

MISES, Ludwing. Sobre liberalismo y capitalismo. Tomo I. Folio, biblioteca de economía. Unión Editorial S.A., Barcelona. [Traducción Joaquín Reig Albiol]. 1996.

MISES, Ludwing. La acción humana. Tratado de economía. Unión Editorial. [Séptima edición- Trad.]. Madrid.

MISES, LUDWING. Política económica. Pensamientos para el hoy y mañana. Buenos Aires: Editorial El ateneo. 1993.

NICHOLSON, Walter. Teoría Microeconómica: principios básicos y ampliaciones. [ 8 a ed.]. Thompson., 2004

ORTIZ, David. El orden sensorial, individualismo y conocimiento económico en la obra de F. A. HAYEK. Rev. Econ. Inst. Vol.11, (20). Bogotá, Junio 2009.

POSNER, Richard. Utilitarismo: economía y teoría jurídica. En Derecho y Economía: una revisión de literatura Andrés Roemer [comp.]. 2000. México: Fondo de Cultura Económica.

SMITH, Adam. Investigación de la naturaleza y causa de la riqueza de las naciones. Libro I. Capítulo V.

ZANOTTI, Gabriel. Fundamentos filosóficos y epistemológicos de la praxeología. Tesis de 1990 para optar por el título de doctor en Filosofía [edición 2002]. Acto Institute. 